\title{
Research on Key Performance of Novel Interleaved Parallel High-Gain DC/DC Converter
}

\author{
Yongle Ai, Xing Li, Qunfeng Liu, and Haijun Tao
}

\begin{abstract}
Due to the problem of the low output voltage of photovoltaic power generation system and the high demand for DC bus voltage in grid connection, a non-isolated high-gain DC/DC converter with a voltage multiplier cell (VMC) structure is proposed. The converter provides equal current between each phase of VMC, the voltage ripple of each stage can be effectively suppressed, and achieve high gain at low duty cycle. The steady-state analysis of the converter in continuous conduction mode is given, and an experimental prototype with an output power of $200 \mathrm{~W}$ is developed. The experimental results show these advantages which are the output voltage level of converter can be adjusted by increasing or decreasing the number of VMC unit according to the demand, and each stage of VMC has equal current, and the voltage ripple can be effectively suppressed, as well as the use of staggered parallel input form suppresses the input current ripple and is controlled easily.
\end{abstract}

Index Terms - DC/DC converter, high gain, non-isolated, voltage multiplier cell.

\section{INTRODUCTION}

$\mathrm{A}_{\mathrm{i}}^{\mathrm{s}}$ $\mathrm{S}$ the contradiction between energy and environmental issues becomes more and more prominent, the development and utilization of renewable energy such as light energy and wind energy has attracted more and more attention [1]. However, the output DC voltage from the photovoltaic panel is low, generally not exceeding $50 \mathrm{~V}$, which cannot meet the requirements of the DC load or the voltage level required on the input side of the grid-connected inverter. According to the different inverter structures, the DC side voltage usually needs to be above $380 \mathrm{~V}$. The traditional Boost converter has been unable to meet the demand, the research of the high gain converter is imperative [2].

High-gain converters can be divided into two types: isolated and non-isolated according to whether they are isolated or not

Manuscript received July 2, 2020; revised August 23, 2020; accepted September 15, 2020. Date of publication December 30, 2020; date of current version December 4, 2020. This work was supported in part by the National Natural Science Foundation of China under Grant 51777060 and in part by Research Project of Science and Technology in Henan Province under Grant 192102210228.

Y. Ai, X. Li, and H. Tao are with School of Electrical Engineering and Automation, Henan Polytechnic University, Jiaozuo 454100, China (e-mail: aiyongle@hpu.edu.cn; 3724883@qq.com; taohj99@hpu.edu.cn).

Q. Liu is with Hebi Electric Power Company, State Grid Henan Electric Power Corporation, Hebi 458000, China (e-mail: 982728309@qq.com).

Digital Object Identifier 10.24295/CPSSTPEA.2020.00030
[3]. The isolated converter achieves a higher voltage gain by increasing the transformer turns ratio, but due to the large input current ripple, low operating efficiency, low power density, large size, high cost, and leakage inductance and EMI, so it is suitable for occasions where there is no high requirement for efficiency [4].

There are many solutions for non-isolated converters, and the specific forms are mainly coupled inductors, converter cascades, switched inductors, switched capacitors, etc. [5][7]. The cascading of multiple Boost converters can effectively increase the gain, but the voltage stress supporting to the switch device and the diode is still high. With the increase of the number of cascades, the power conversion efficiency decreases, and the stability of the converter is difficult to maintain [8]-[10]. Literature [11] combined with switched capacitors and inductors to form a high-gain structure, which reduced the voltage stress of diodes and switch device, but made the circuit structure to complex. Literature [12] proposed a non-isolated modular multiinput high-gain DC/DC converter topology, each input source corresponds to an input module, and as the number of modules increases, the converter voltage gain increases, but each input module use more inductances, capacitances and switches, so the structure of the converter is complex, and the overall efficiency is difficult to improve. The converter topology proposed in [13] is based on a diode capacitor boosting unit. The structure and control of the converter is simple relatively. In theory, the number of input sources can be infinitely increased and each input source is independent of each other, but the voltage gain of this topology is low. Achieving a higher transformation ratio requires the use of more booster units, and the diodes connected in series at the input end will greatly reduce the efficiency of the circuit. Literature [14]-[15] improves the output voltage gain by connecting a switched capacitor structure to the three-port network of the Boost converter. The number of boost units can be adjusted according to demand. The structure is simple and the input current ripple is small, but when the power increases, the loss increases, the efficiency is difficult to improve, suitable for small power occasions.

In order to achieve higher voltage gain and reduce the voltage stress of the switching device, this paper uses a twophase interleaved parallel technology combined with a boost unit to propose a new type of non-isolated high-gain DC/ DC converter, which has small input current ripple and gain features of high coefficient. The article first gives the working principle in continuous conduction mode, then gives the 


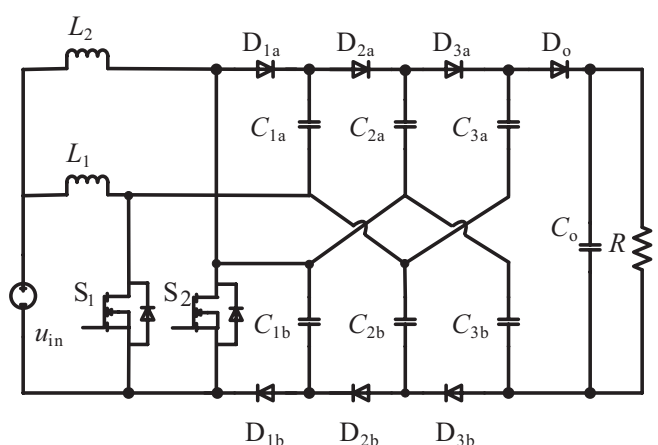

Fig. 1. High voltage Boost converter.

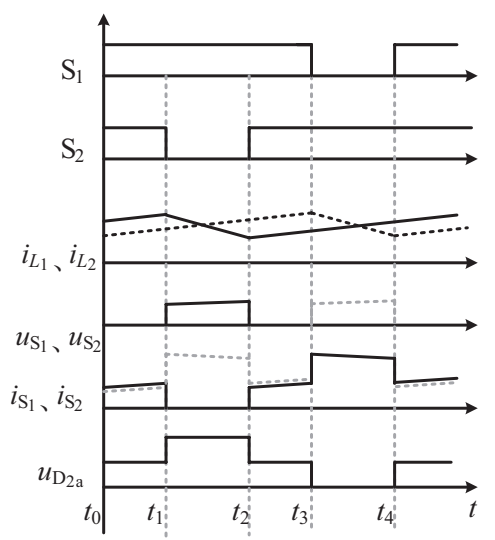

Fig. 2. Part of the waveform within a switching period $T_{\mathrm{s}}$.

steady-state characteristics, and finally gives the corresponding experimental results.

\section{Principle of the Proposed Converter}

The topology of the interleaved parallel high-gain DC/DC converter proposed in this paper is shown in Fig. 1. The input power $V_{\text {in }}$, the switch devices $\mathrm{S}_{1}, \mathrm{~S}_{2}$ and the inductors $L_{1}, L_{2}$ together form a staggered parallel structure. The capacitors $C_{1 \mathrm{a}}-C_{3 \mathrm{~b}}$ and the diodes $\mathrm{D}_{1 \mathrm{a}}-\mathrm{D}_{3 \mathrm{~b}}$ form a VMC. $C_{0}$ is used as filter capacitor to supply power to load $R$.

To simplify the analysis process, the following assumptions are made:

(1) The inductor current $i_{L_{1}}, i_{L_{2}}$ are continuous;

(2) Each capacitor is large enough to ignore the ripple on all capacitors;

(3) All devices are ideal, ignoring the influence of parasitic parameters.

(4) The switches $S_{1}$ and $S_{2}$ adopt interleaved control, the driving signals are the same, but the phases are different by $180^{\circ}$, and the duty ratios are equal and greater than 0.5 .

This article only discusses the case where the duty cycle D $>0.5$, that is, when $\mathrm{D}=0.65$, Part of the working waveforms of each device of the converter in a switching cycle $T_{\mathrm{s}}$ is shown in Fig. 2. According to the different turn-on and turn-off conditions of the switches $\mathrm{S}_{1}$ and $\mathrm{S}_{2}$, the switching state of the converter can be divided into the following four modes within one switching period $T_{\mathrm{s}}$. The equivalent circuit diagrams of

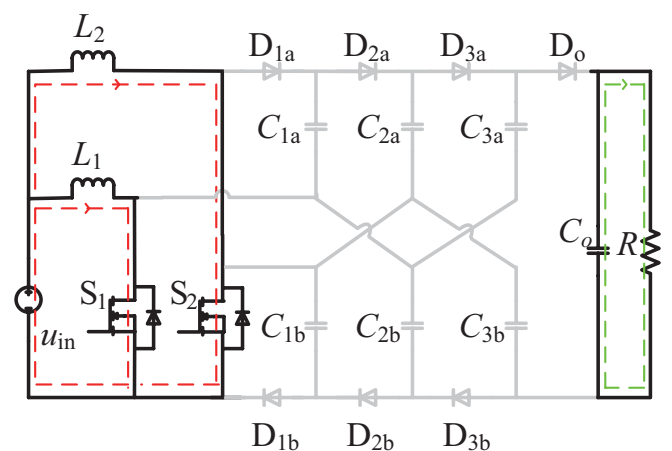

(a)

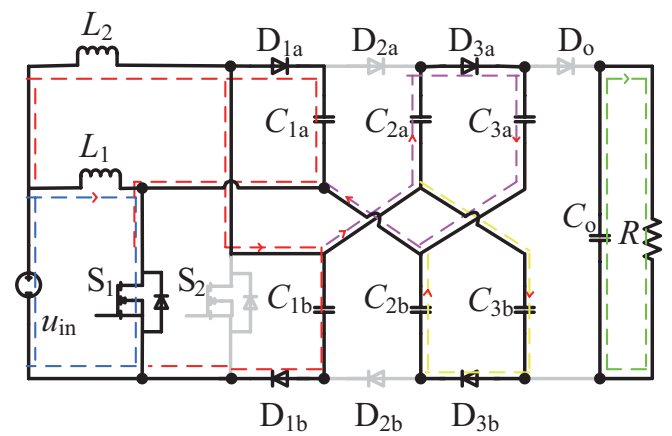

(b)

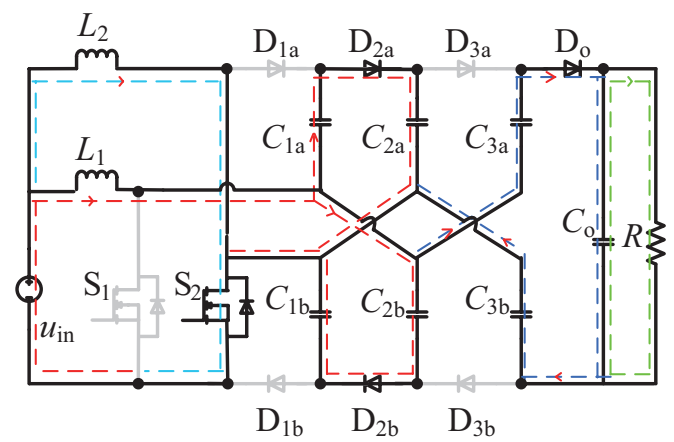

(c)

Fig. 3. The equivalent circuit. (a) Mode 1. (b) Mode 2. (c) Mode 4.

various switching modes are shown in Fig. 3.

Switch mode $1\left[t_{0}-t_{1}\right]$ (shown in Fig. 3(a)): In this switch mode, the switches $\mathrm{S}_{1}$ and $\mathrm{S}_{2}$ are all on and all diodes are off. The input power source charges the inductors $L_{1}$ and $L_{2}$ through switches $S_{1}$ and $S_{2}$ respectively. The voltage across the inductors $L_{1}$ and $L_{2}$ is the input voltage. The currents $i_{L_{1}}$ and $i_{L_{2}}$ flowing in $L_{1}$ and $L_{2}$ rise linearly, and all the capacitor voltages in the converter remain unchanged. Capacitor $C_{0}$ supplies power to the load. At time $t_{1}, \mathrm{~S}_{2}$ is turned off, $\mathrm{S}_{1}$ continues to be turned on, the time for switch mode 1 is over, The relationship between variables in switch mode 1 is shown in (1),

$$
u_{L_{1}}=u_{L_{2}}=u_{\text {in }}
$$

Switching mode $2\left[t_{1}-t_{2}\right]$ (shown in Fig. 3(b)): At time $t_{1}, \mathrm{~S}_{2}$ is turned off, $\mathrm{S}_{1}$ continues to remain on, the inductor current $i_{L_{1}}$ continues to rise linearly, $i_{L_{2}}$ decreases linearly, and the current $i_{L_{2}}$ of inductor $L_{2}$ flows through the diode $\mathrm{D}_{1 \mathrm{a}}, \mathrm{D}_{1 \mathrm{~b}}, \mathrm{D}_{3 \mathrm{a}}$ and $\mathrm{D}_{3 \mathrm{~b}}$, 
and the capacitors $C_{1 \mathrm{a}}, C_{1 \mathrm{~b}}$ and $C_{3 \mathrm{a}}$ are charged. During this time, the inductance $L_{2}$ and the capacitor $C_{2 \mathrm{a}}$ are discharged. Therefore, the capacitor voltages $u_{C_{1 \mathrm{a}}}, u_{C_{1 \mathrm{~b}}}$ and $u_{C_{3 \mathrm{a}}}$ rise, and $u_{C_{2 \mathrm{a}}}$ decreases. At time $t_{2}$, switch $\mathrm{S}_{2}$ is turned on, the time of switch mode 2 is over. The relationship between variables in switch mode 2 is shown in (2),

$$
\left\{\begin{aligned}
u_{L_{1}} & =u_{\text {in }} \\
u_{L_{2}} & =u_{\text {in }}-u_{C_{1 \mathrm{a}}}=u_{\text {in }}-u_{C_{1 \mathrm{~b}}}=u_{\text {in }}+u_{C_{2 \mathrm{a}}}-u_{C_{3 \mathrm{a}}} \\
& =u_{\text {in }}+u_{C_{2 \mathrm{a}}}-u_{C_{3 \mathrm{~b}}}
\end{aligned}\right.
$$

Switch mode $3\left[t_{2}-t_{3}\right]$ : The same as mode 1 .

Switch mode $4\left[t_{3}-t_{4}\right]$ (shown in Fig. 3(c)): Switch $\mathrm{S}_{1}$ is turned off at time $t_{3}, \mathrm{~S}_{2}$ remains on, the inductor current $i_{L_{2}}$ rises linearly, $i_{L_{1}}$ continues to fall down linearly, and the current of inductor $L_{1}$ flows through diode $\mathrm{D}_{2 \mathrm{a}}, \mathrm{D}_{2 \mathrm{~b}}, \mathrm{D}_{3 \mathrm{a}}$ and $\mathrm{D}_{0}$ and the capacitors $C_{2 \mathrm{a}}, C_{2 \mathrm{~b}}$ and $C_{0}$ are charged. During this process, the inductance $L_{1}$, capacitors $C_{1 \mathrm{a}}, C_{1 \mathrm{~b}}, C_{3 \mathrm{a}}$ and $C_{3 \mathrm{~b}}$ are in a discharged state, so the capacitor voltage in $u_{C_{2 \mathrm{a}}}, u_{C_{2 \mathrm{~b}}}$ and $u_{C_{0}}$ rises, and $u_{C_{1 \mathrm{a}}}, u_{C_{1 \mathrm{~b}}}, u_{C_{3 \mathrm{a}}}$ and $u_{C_{3 \mathrm{~b}}}$ fall down. At time $t_{4}$, the switch $\mathrm{S}_{1}$ is turned on, the time of switch mode 3 is over, the current cycle ends, and the next cycle is entered. The relationship between variables in switch mode 3 is shown in (3),

$$
\left\{\begin{aligned}
u_{L_{2}} & =u_{\text {in }} \\
u_{L_{1}} & =u_{\text {in }}+u_{C_{1 \mathrm{a}}}-u_{C_{2 \mathrm{a}}}=u_{\text {in }}+u_{C_{1 \mathrm{~b}}}-u_{C_{2 \mathrm{~b}}} \\
& =u_{\mathrm{in}}+u_{C_{3 \mathrm{a}}}+u_{C_{3 \mathrm{~b}}}-u_{0}
\end{aligned}\right.
$$

\section{Steady State Analysis}

\section{A. Voltage Gain}

According to the principle of the volt-second balance for the inductor $L_{1}$, there will have following (4)

$$
\left\{\begin{array}{l}
u_{\text {in }} \cdot D=\left(u_{C_{2 \mathrm{~b}}}-u_{\text {in }}-u_{C_{\mathrm{lb}}}\right) \cdot(1-D) \\
u_{\text {in }} \cdot D=\left(u_{C_{2 \mathrm{a}}}-u_{\text {in }}-u_{C_{\mathrm{la}}}\right) \cdot(1-D) \\
u_{\text {in }} \cdot D=\left(u_{C_{\mathrm{o}}}-u_{\text {in }}-u_{C_{3 \mathrm{a}}}-u_{C_{3 \mathrm{~b}}}\right) \cdot(1-D)
\end{array}\right.
$$

Same as $L_{1}$, there will have following (5) for $L_{2}$

$$
\left\{\begin{array}{l}
u_{\text {in }} \cdot D=\left(u_{C_{1 \mathrm{a}}}-u_{\text {in }}\right)(1-D) \\
u_{\text {in }} \cdot D=\left(u_{C_{1 \mathrm{~b}}}-u_{\text {in }}\right)(1-D) \\
u_{\text {in }} \cdot D=\left(u_{C_{3 \mathrm{a}}}-u_{\text {in }}-u_{C_{2 \mathrm{a}}}\right)(1-D) \\
u_{\text {in }} \cdot D=\left(u_{C_{3 \mathrm{~b}}}-u_{\text {in }}-u_{C_{2 \mathrm{~b}}}\right)(1-D)
\end{array}\right.
$$

From the circuit topology of switch modes 2 and 3,

$$
\left\{\begin{array}{l}
u_{C_{1 \mathrm{a}}}=u_{C_{1 \mathrm{~b}}} \\
u_{C_{2 \mathrm{a}}}=u_{C_{2 \mathrm{~b}}} \\
u_{C_{3 \mathrm{a}}}=u_{C_{3 \mathrm{~b}}}
\end{array}\right.
$$

From (4)-(6), the following (7) can be obtained,

$$
\left\{\begin{array}{c}
u_{C_{1 \mathrm{a}}}=u_{C_{\mathrm{lb}}}=\frac{u_{\text {in }}}{1-D} \\
u_{C_{2 \mathrm{a}}}=u_{C_{2 \mathrm{~b}}}=\frac{2 u_{\text {in }}}{1-D} \\
u_{C_{3 \mathrm{a}}}=u_{C_{3 \mathrm{~b}}}=\frac{3 u_{\text {in }}}{1-D} \\
u_{\mathrm{o}}=\frac{7 u_{\text {in }}}{1-D}
\end{array}\right.
$$

So the voltage gain is,

$$
M=\frac{u_{\mathrm{o}}}{u_{\text {in }}}=\frac{7}{1-D}
$$

It can be found from (9) that the voltage gain of the converter increases with the increase of the duty cycle, which can achieve high gain while avoiding the situation of the limit duty cycle.

\section{B. Voltage Stress of Switch Device and Diode}

Analyze the working principle in continuous conduction mode, the $u_{\mathrm{vS} 1}$ and $u_{\mathrm{vS}_{2}}$ are the voltage stress of the switches of the converter, respectively.

$$
u_{\mathrm{vS}}=u_{\mathrm{vS}_{2}}=u_{C_{1 \mathrm{a}}}=\frac{1}{7} u_{\mathrm{o}}
$$

The voltage stress of diodes $\mathrm{D}_{1 \mathrm{a}}, \mathrm{D}_{2 \mathrm{a}}, \mathrm{D}_{3 \mathrm{a}}, \mathrm{D}_{1 \mathrm{~b}}, \mathrm{D}_{2 \mathrm{~b}}, \mathrm{D}_{3 \mathrm{~b}}$ and $\mathrm{D}_{0}$, are $u_{\mathrm{vpD}_{1 \mathrm{a}}}, u_{\mathrm{vpD}_{2 \mathrm{a}}}, u_{\mathrm{vpD}_{3 \mathrm{a}}}, u_{\mathrm{vpD}_{1 \mathrm{~b}}}, u_{\mathrm{vpD}_{2 \mathrm{~b}}}, u_{\mathrm{vpD}} \mathrm{b}$ and $u_{\mathrm{vpD}}$, then

$$
u_{\mathrm{vpD}_{1 \mathrm{a}}}=\ldots=u_{\mathrm{vpD}_{3 \mathrm{~b}}}=u_{\mathrm{vpD}_{0}}=u_{\mathrm{C}_{2 \mathrm{a}}}=\frac{2}{7} u_{0}
$$

Compared with the steady-state characteristics of the traditional boost converter, the voltage stresses of the switches $\mathrm{S}_{1}, \mathrm{~S}_{2}$ and diodes $\mathrm{D}_{1 \mathrm{a}}, \mathrm{D}_{1 \mathrm{~b}}, \mathrm{D}_{2 \mathrm{a}}, \mathrm{D}_{2 \mathrm{~b}}, \mathrm{D}_{3 \mathrm{a}}, \mathrm{D}_{3 \mathrm{~b}}$, and $\mathrm{D}_{0}$ in the proposed converter are significantly reduced, Respectively $1 / 7$ and $2 / 7$ of the voltage stress of the traditional boost converter. It is beneficial to protect the switching device, reduce the loss, and improve the transmission efficiency of the converter.

\section{Current Stress of Switch Device and Diode}

Because the currents of the inductors $L_{1}$ and $L_{2}$ are always flowing at the continuous conduction mode, the inductor current ripple can be ignored, and the two inductor currents can be replaced by the average value, namely as $I_{L_{1}}$ and $I_{L_{2}}$ respectively. The diode current in the converter is expressed as an average value, ignoring the current ripple during the diode conduction period. Ignore the ripple of the input current $i_{\text {in }}$, and set its average value to $I_{\text {in }}$. When the converter is operating in steady state, the average current that all capacitors flow in a cycle is 0 , that is, they must meet the ampere-second balance.

$I_{\mathrm{S}_{1}}$ and $I_{\mathrm{S}_{2}}$ are the average current values of switches $\mathrm{S}_{1}$ 
and $\mathrm{S}_{2}$, and $I_{\mathrm{D}_{1 a}}, I_{\mathrm{D}_{2 a}}, I_{\mathrm{D}_{3 a}}, I_{\mathrm{D}_{1 b}}, I_{\mathrm{D}_{2 b}}, I_{\mathrm{D}_{3 b}}$ and $I_{\mathrm{D}_{0}}$ are the average current values of diodes $\mathrm{D}_{1 \mathrm{a}}, \mathrm{D}_{2 \mathrm{a}}, \mathrm{D}_{3 \mathrm{a}}, \mathrm{D}_{1 \mathrm{~b}}, \mathrm{D}_{2 \mathrm{~b}}, \mathrm{D}_{3 \mathrm{~b}}$ and $\mathrm{D}_{0}$, respectively. In a switching cycle, the switch $\mathrm{S}_{1}$ only has current flowing when switching modes 1,2 and 3 , so the current flowing through the switch $\mathrm{S}_{1}$ in mode 1 is the inductor current $I_{L_{1}}$, and the duration is $(2 D-1) T_{\mathrm{s}}$; In mode 2 , the switch $\mathrm{S}_{2}$ is turned off, the current of the inductor $L_{2}$ flows through the four branches, but only three flows through the switch $\mathrm{S}_{1}$, the duration is $(1-D) T_{s}$; the analysis process of the switch $S_{2}$ is similar to the above process, so it can be the average currents $I_{\mathrm{S}_{1}}$ and $I_{\mathrm{S}_{2}}$ of switches $\mathrm{S}_{1}$ and $\mathrm{S}_{2}$ are obtained as

$$
\left\{\begin{array}{l}
I_{\mathrm{S}_{1}}=(2 D-1) I_{L_{1}}+(1-D)\left(I_{L_{1}}+I_{L_{2}}\right)=\frac{4-D}{7} I_{\mathrm{in}} \\
I_{\mathrm{S}_{2}}=(2 D-1) I_{L_{2}}+(1-D)\left(I_{L_{1}}+I_{L_{2}}\right)=\frac{3+D}{7} I_{\mathrm{in}}
\end{array}\right.
$$

Because the average value of the current through each capacitor in a cycle is 0 , so

$$
I_{\mathrm{D}_{\mathrm{la}}}=I_{\mathrm{D}_{2 \mathrm{a}}}=\ldots=I_{\mathrm{D}_{3 \mathrm{~b}}}=I_{\mathrm{D}_{0}}
$$

Also

$$
\left\{\begin{array}{l}
I_{\mathrm{D}_{1 \mathrm{a}}}+I_{\mathrm{D}_{1 \mathrm{~b}}}+I_{\mathrm{D}_{3 \mathrm{a}}}+I_{\mathrm{D}_{3 \mathrm{~b}}}=(1-D) I_{L_{2}} \\
I_{\mathrm{D}_{2 \mathrm{a}}}+I_{\mathrm{D}_{2 \mathrm{~b}}}+I_{\mathrm{D}_{0}}=(1-D) I_{L_{1}}
\end{array}\right.
$$

From above equations, it can obtain (15) and (16)

$$
\begin{gathered}
I_{\mathrm{D}_{\mathrm{la}}}=I_{\mathrm{D}_{\mathrm{lb}}}=I_{\mathrm{D}_{2 \mathrm{a}}}=I_{\mathrm{D}_{2 \mathrm{~b}}}=I_{\mathrm{D}_{3 \mathrm{a}}}=I_{\mathrm{D}_{3 \mathrm{~b}}}=I_{\mathrm{D}_{0}}=\frac{1-D}{7} I_{\mathrm{in}} \\
\left\{\begin{array}{l}
I_{L_{1}}=\frac{3}{7} I_{\mathrm{in}} \\
I_{L_{2}}=\frac{4}{7} I_{\mathrm{in}}
\end{array}\right.
\end{gathered}
$$

It can be found from equation (16) that the inductor current is $3 / 7$ and $4 / 7$ of the traditional boost converter inductor current respectively. This will reduce the DC loss of the inductor and will also be beneficial to improve the transmission efficiency of the converter.

\section{Comparisons of Boost Converters}

Comparing the proposed converter with [13]-[15], the curve of voltage gain versus duty cycle is shown in Fig. 4. It can be seen that the proposed converter can achieve high gain at relatively small duty cycle. Table I shows the comparison results of voltage gain, switches and diode voltage stress, as well as the number of components used and the continuity of input current at the same complexity. It can be seen from the Table I that the components used in [13] are the least, but the voltage gain is low, [15] has the same voltage stress of switches and diodes, but the voltage gain of [15] has been greatly improved.

\begin{tabular}{|c|c|c|c|c|}
\hline Parameters & [13] & [14] & {$[15]$} & Proposed \\
\hline \multirow{2}{*}{ Voltage gain } & \multirow{2}{*}{3} & 4 & 3 & 7 \\
\hline & & $\overline{1-D}$ & $D(1-D)$ & $\overline{1-D}$ \\
\hline Voltage stress & 1 & 1 & 1 & 1 \\
\hline on switches & $\frac{-}{3} u_{o}$ & $\overline{4}^{u_{o}}$ & $\frac{-}{3} u_{o}$ & $\overline{7}^{u_{o}}$ \\
\hline Voltage stress & 1 & 1 & 1 & 2 \\
\hline on diodes & $\frac{-}{3} u_{o}$ & $\overline{2}^{u_{o}}$ & $\frac{-}{3} u_{o}$ & $\overline{7}^{u_{o}}$ \\
\hline $\begin{array}{l}\text { Continuous } \\
\text { input current }\end{array}$ & yes & yes & yes & yes \\
\hline $\begin{array}{l}\text { No. of } \\
\text { switches }\end{array}$ & 2 & 2 & 2 & 2 \\
\hline No. of diodes & 4 & 8 & 6 & 7 \\
\hline $\begin{array}{l}\text { No. of } \\
\text { capacitors }\end{array}$ & 4 & 7 & 6 & 7 \\
\hline
\end{tabular}

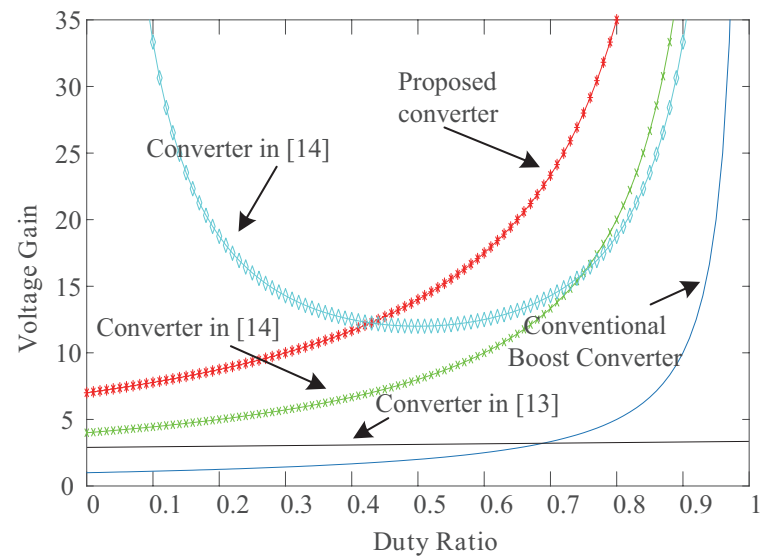

Fig. 4. Voltage gain comparison of Boost converters.

TABLE I

Comparison of Steady State Characteristics and Component Usage

\section{EXPERIMENTAL VERIFICATION}

In order to verify the validity of the proposed converter and the correctness of theoretical analysis, simulation verification and experimental prototype verification were built.

\section{A. Small Signal Modeling}

In order to further study the steady-state process and dynamic performance of the converter, a small signal model is established and an effective controller is designed. The average equation of state in continuous conduction mode can be expressed as,

$$
\left\{\begin{array}{l}
L_{1} \frac{\mathrm{d}\left\langle i_{L_{1}}\right\rangle}{\mathrm{d} t}=\left\langle u_{\text {in }}\right\rangle-\frac{1}{7}(1-\mathrm{d})\left\langle u_{\mathrm{o}}\right\rangle \\
L_{2} \frac{\mathrm{d}\left\langle i_{L_{L}}\right\rangle}{\mathrm{d} t}=\left\langle u_{\text {in }}\right\rangle-\frac{1}{7}(1-\mathrm{d})\left\langle u_{\mathrm{o}}\right\rangle \\
C_{1 \mathrm{a}} \frac{\mathrm{d}\left\langle u_{C_{1 \mathrm{a}}}\right\rangle}{\mathrm{d} t}=\ldots \ldots C_{3 \mathrm{~b}} \frac{\mathrm{d}\left\langle u_{C_{3 \mathrm{~b}}}\right\rangle}{\mathrm{d} t}=0 \\
C_{\mathrm{o}} \frac{\mathrm{d}\left\langle u_{C_{\mathrm{o}}}\right\rangle}{\mathrm{d} t}=\frac{1}{7}(1-\mathrm{d})\left\langle i_{\text {in }}\right\rangle-\frac{\left\langle u_{\mathrm{o}}\right\rangle}{R} \\
\left\langle i_{\text {in }}\right\rangle=\left\langle i_{L_{1}}\right\rangle+\left\langle i_{L_{2}}\right\rangle
\end{array}\right.
$$


Among them, $\left\langle i_{L_{1}}\right\rangle,\left\langle i_{L_{2}}\right\rangle,\left\langle u_{\mathrm{in}}\right\rangle,\left\langle u_{0}\right\rangle,\left\langle u_{C_{\mathrm{la}}}\right\rangle \ldots\left\langle u_{C_{3 \mathrm{~b}}}\right\rangle,\left\langle u_{C_{0}}\right\rangle$ are the average value of $i_{L_{1}}, i_{L_{2}}, u_{C_{1 a}} \ldots . . u_{C_{3 \mathrm{~b}}}, u_{C 0}$. The perturbation is added to them, and all of them satisfy the formula (18),

$$
\left\{\begin{array} { l } 
{ \langle u _ { \text { in } } \rangle = U _ { \text { in } } + \hat { u } _ { \text { in } } } \\
{ d = D + \hat { d } } \\
{ \langle i _ { L _ { 1 } } \rangle = I _ { L _ { 1 } } + \hat { i } _ { L _ { 1 } } } \\
{ \langle i _ { L _ { 2 } } \rangle = I _ { L _ { 2 } } + \hat { i } _ { L _ { 2 } } } \\
{ \langle i _ { \text { in } } \rangle = I _ { L _ { 1 } } + I _ { L _ { 2 } } + \hat { i } _ { L _ { 1 } } + \hat { i } _ { L _ { 2 } } } \\
{ \langle u _ { \mathrm { o } } \rangle = U _ { \mathrm { o } } + \hat { u } _ { \mathrm { o } } }
\end{array} \quad \left\{\begin{array}{l}
\hat{u}_{\mathrm{in}} \ll U_{\mathrm{in}} \\
\hat{d} \ll<D \\
\hat{i}_{L_{1}} \ll I_{L_{1}} \\
\hat{i}_{L_{2}} \ll I_{L_{2}} \\
\hat{i}_{\text {in }} \ll i_{\text {in }} \\
\hat{u}_{\mathrm{o}} \ll U_{\mathrm{o}}
\end{array}\right.\right.
$$

By introducing (18) into (17), and eliminating DC component and omitting high-order component, the linear equivalent (19) of AC small signal is obtained,

$$
\left\{\begin{array}{l}
L_{1} \frac{\mathrm{d} \hat{i}_{L_{1}}}{\mathrm{~d} t}=\hat{u}_{\mathrm{in}}-\frac{1}{7}(1-D) \hat{u}_{\mathrm{o}}+\frac{1}{7} U_{\mathrm{o}} \hat{d} \\
L_{2} \frac{\mathrm{d} \hat{i}_{L_{2}}}{\mathrm{~d} t}=\hat{u}_{\mathrm{in}}-\frac{1}{7}(1-D) \hat{u}_{\mathrm{o}}+\frac{1}{7} U_{\mathrm{o}} \hat{d} \\
C_{\mathrm{o}} \frac{\mathrm{d} u_{C_{0}}}{\mathrm{~d} t}=\frac{1}{7}(1-D) \hat{i}_{\mathrm{in}}-\frac{1}{7} I_{\text {in }} \hat{d}-\frac{\hat{u}_{\mathrm{o}}}{R} \\
\hat{i}_{\text {in }}=\hat{i}_{L_{1}}+\hat{i}_{L_{2}}
\end{array}\right.
$$

By Laplace transformation of (19), the control output voltage transfer function $G_{\mathrm{ud}}(s)$ and the control input current transfer function $G_{\text {id }}(s)$ can be obtained,

$$
\begin{aligned}
& G_{\text {ud }}(s)=\left.\frac{\hat{u}_{\mathrm{o}}(s)}{\hat{d}(s)}\right|_{\hat{u}_{\mathrm{m}}(s)=0}=\frac{U_{\mathrm{o}} \mathrm{ab}-7 s L_{1} L_{2} I_{\text {in }}}{7 s L_{1} L_{2}\left(\frac{7}{R}+7 s C_{\mathrm{o}}\right)+a^{2} b} \\
& G_{\text {id }}(s)=\left.\frac{\hat{i}_{\text {in }}(s)}{\hat{d}(s)}\right|_{\hat{u}_{\mathrm{m}}(s)=0}=\frac{\left[\left(\frac{7}{R}+7 s C_{\mathrm{o}}\right) U_{\mathrm{o}}+a I_{\text {in }}\right] b}{7 s L_{1} L_{2}\left(\frac{7}{R}+7 s C_{\mathrm{o}}\right)+a^{2} b}
\end{aligned}
$$

Where

$$
a=1-D, b=L_{1}+L_{2}
$$

The double closed-loop control strategy is adopted and the controller is designed according to the transfer functions shown in (20) and (21).

According to the control block diagram shown in Fig. 5, the converter is simulated to study the anti-interference ability of the converter. As shown in Fig. 6, when $t=0.25 \mathrm{~s}$, the input voltage jumps from $20 \mathrm{~V}$ to $25 \mathrm{~V}$, the dynamic response time of voltage closed-loop control is about $0.16 \mathrm{~s}$, and the dynamic response time of double closed-loop control is about

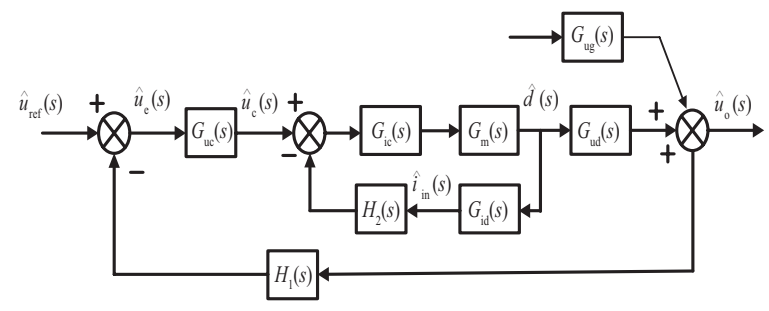

Fig. 5. Block diagram of double closed loop control system.

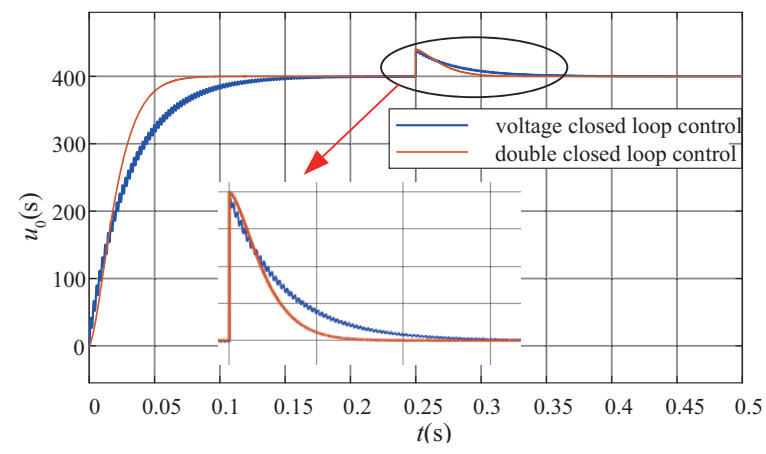

Fig. 6. Comparison between voltage closed loop control and double closed loop control.

TABLE II

PARAMETERS Listed UsEd in SimUlation

\begin{tabular}{lc}
\hline \hline Parameter & Value \\
\hline Input voltage $V_{\mathrm{in}} / \mathrm{V}$ & 20 \\
Output voltage $V_{0} / \mathrm{V}$ & 400 \\
Output load $R / \Omega$ & 800 \\
Switching frequency $f_{\mathrm{s}} / \mathrm{kHz}$ & 100 \\
Inductance $L_{1}, L_{2} / \mu \mathrm{H}$ & 100 \\
Capacitance $C_{1 \mathrm{a}}-C_{3 \mathrm{~b}} / \mu \mathrm{F}$ & 10 \\
Capacitance $C_{0} / \mu \mathrm{F}$ & 22 \\
\hline \hline
\end{tabular}

$0.08 \mathrm{~s}$, which has better anti-interference ability than double closed-loop control. Where $H_{1}=0.05, H_{2}=0.3, u_{\text {ref }}=2 \mathrm{~V}$, $G_{\text {uс }}(s)=0.2\left(1+\frac{1}{0.001 s}\right), G_{\text {iс }}(s)=0.4\left(1+\frac{1}{0.25 \times 10^{-4} s}\right)$.

\section{B. Simulation Verification}

Based on MATLAB/simulink simulation environment, a staggered parallel high-gain converter model was built for simulation. The specific parameters in the circuit are shown in Table II.

The experimental waveforms measured according to the simulation model are shown in Fig. 7. It can be seen from Fig. 7(a) and (b) that the duty ratios $D_{1}$ and $D_{2}$ of the switch devices $\mathrm{S}_{1}$ and $\mathrm{S}_{2}$ are $D=0.65$, and the input voltage and output voltage are $20 \mathrm{~V}$ and $400 \mathrm{~V}$, respectively, where high gain can be achieved by working at a low duty cycle, and the result is consistent with theoretical analysis. The waveforms 


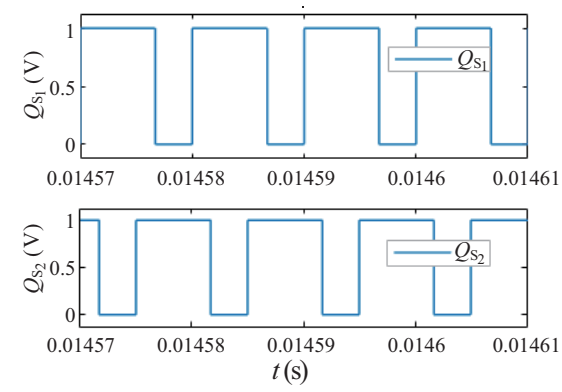

(a)

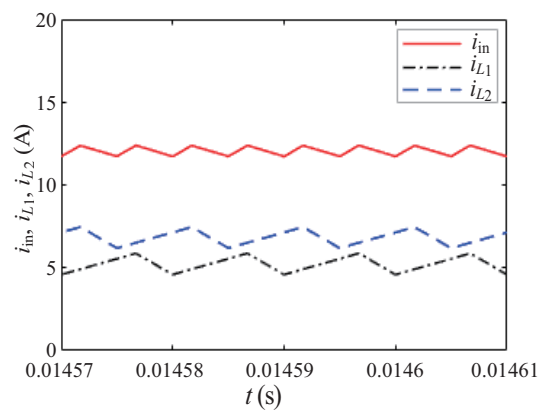

(c)
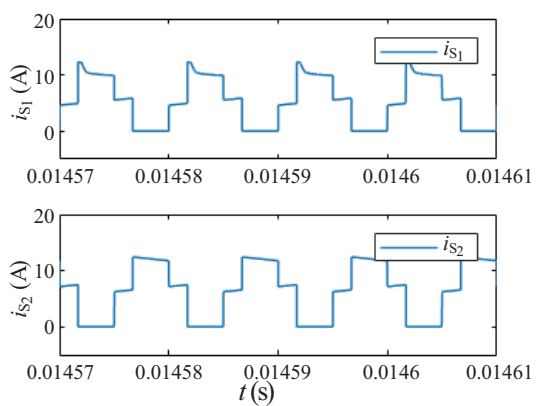

(e)

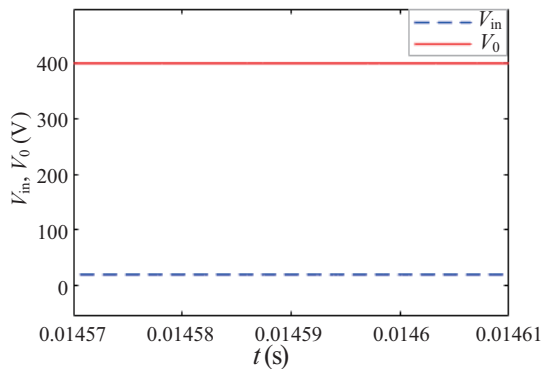

(b)
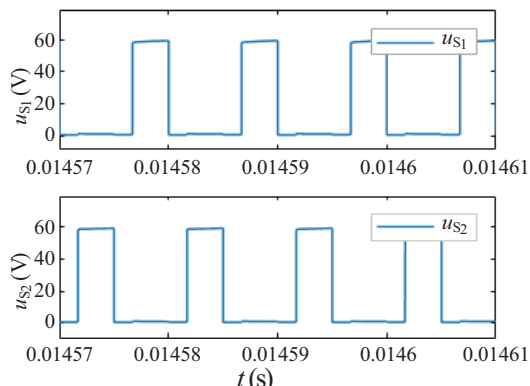

(d)

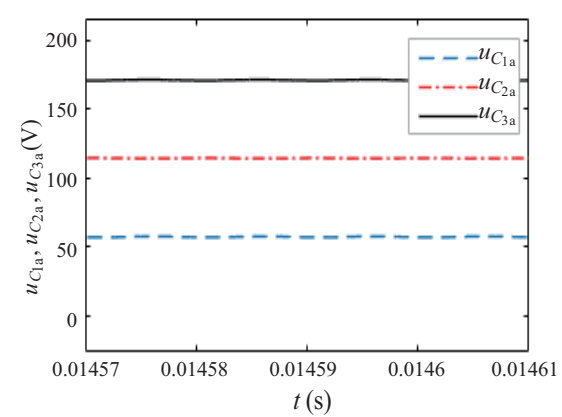

(f)

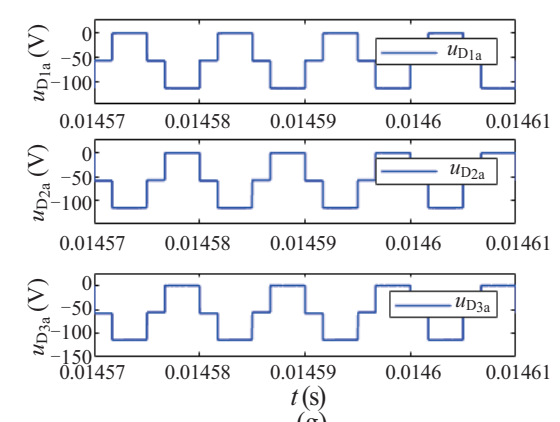

(g)

Fig. 7. Simulation waveform.

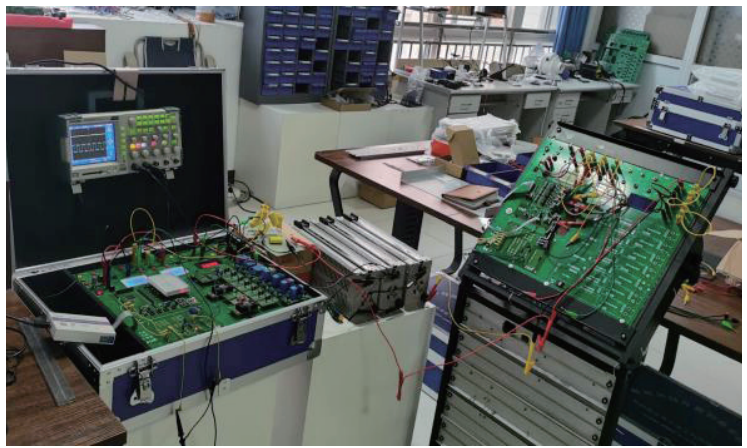

Fig. 8. Experimental prototype.

of the input current $i_{\text {in }}$ and the inductor currents $i_{L_{1}}$ and $i_{L_{2}}$ are shown as Fig. 7(c). It can be seen that the average values of the inductor currents $i_{L_{1}}$ and $i_{L_{2}}$ are similar, which can automatically share the current and reduce the inductor current stress. The ripple frequency of the input current $i_{\text {in }}$ is twice the ripple frequency of the inductor current $i_{L_{1}}$ and $i_{L_{2}}$, and the size of the converter can be reduced due to the input current ripple reducing.

\section{Experimental Verification}

Based on the above analysis, an experimental prototype with a rated power of $200 \mathrm{~W}$ is built, as shown in Fig. 8, and the specific parameters are shown in Table II. The switch device is IRFP264, and the diode is MUR840.

Through the test of the above prototype, the main experimental waveforms obtained are shown in Fig. 9.

It can be seen from Fig. 9(a) that the duty ratio $D=0.65$ of the switch $\mathrm{S}_{1}$ and $\mathrm{S}_{2}$, working in the low duty cycle state, the currents through the two inductors $L_{1}$ and $L_{2}$ are close to each other, and the phases are different from each other by $180^{\circ}$. The result from the experiment is consistent with the above analysis of the input current, and the input current ripple is effectively suppressed. It can be seen from Fig. $9\left(b_{1}\right)-\left(b_{3}\right)$ that the voltage stress of the two switch tubes is about $57 \mathrm{~V}$, which is $1 / 7$ of the output voltage, and the voltage stress of the diode is about $114 \mathrm{~V}$, which is $2 / 7$ of the output voltage. The result from the experiment is consistent with the analysis result of (10) and (11).

Also from Fig. $9\left(c_{1}\right)$ and $\left(c_{2}\right)$ it can be seen that the input and output voltage are $20 \mathrm{~V}$ and $400 \mathrm{~V}$, respectively. The 


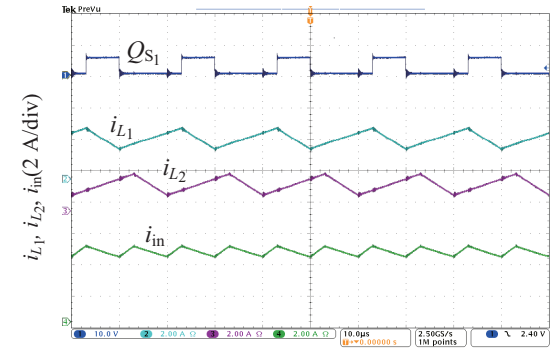

(a)

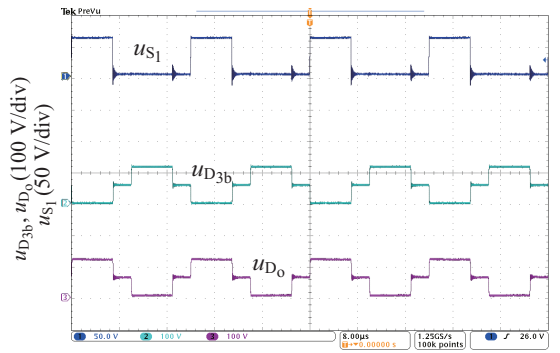

(b3)

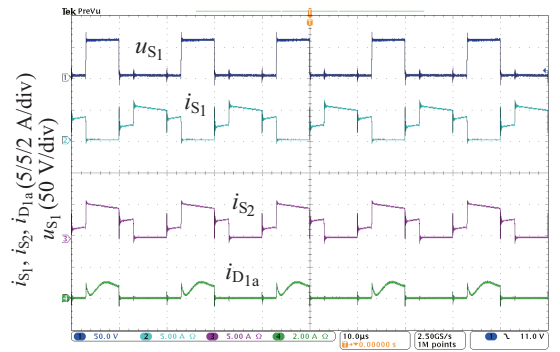

(d)

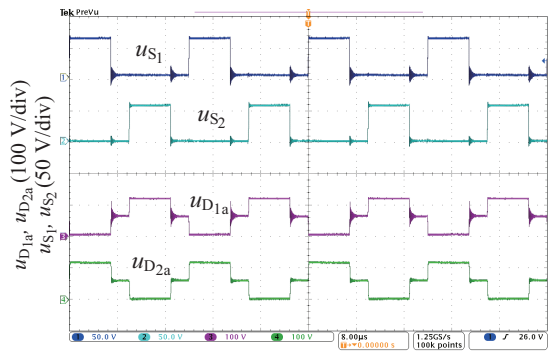

(b1)

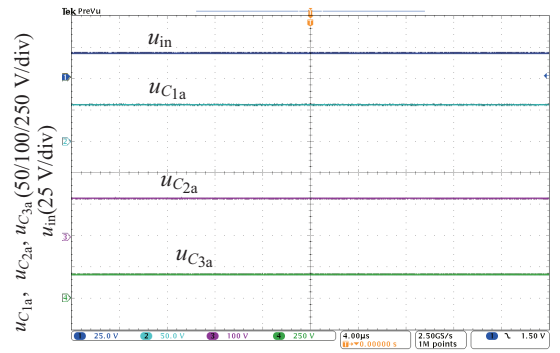

(c1)

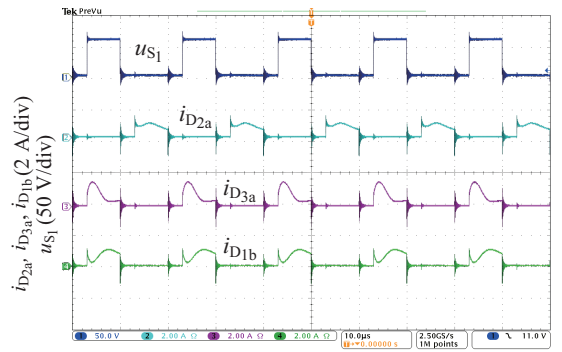

(e)

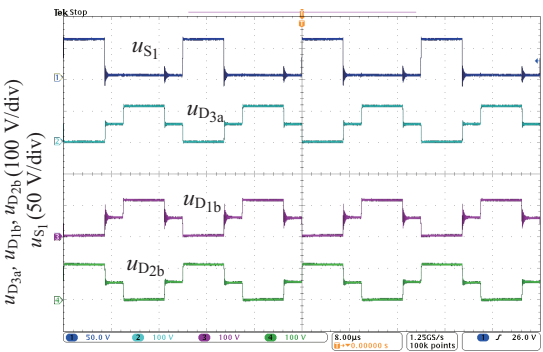

(b2)

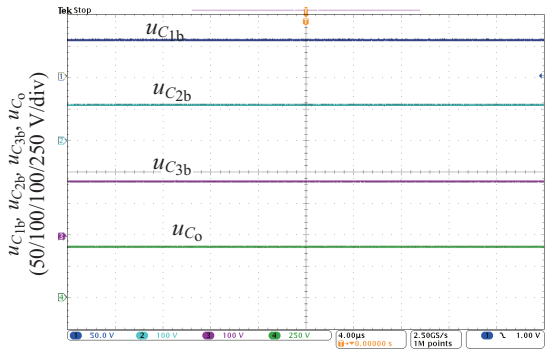

(c2)

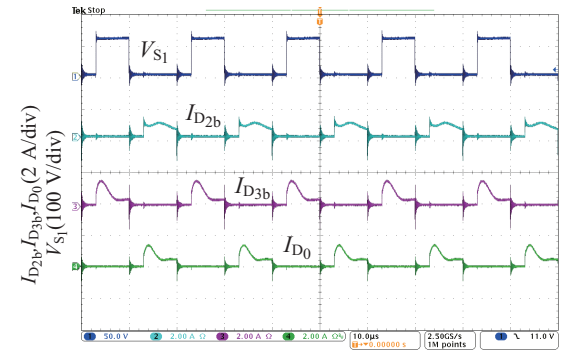

(f)

Fig. 9. Experimental waveforms.

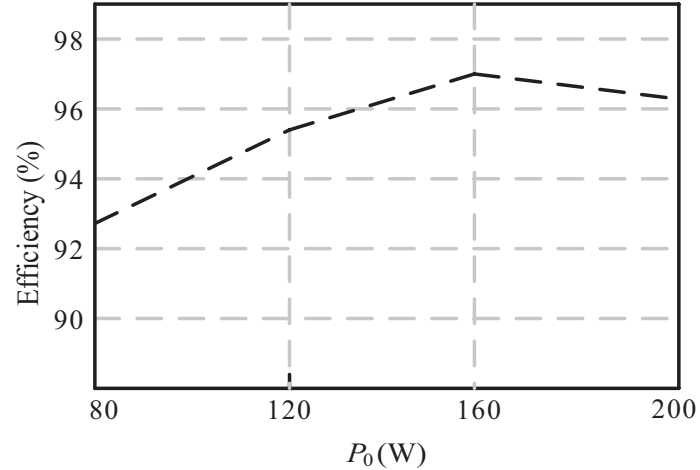

Fig. 10. Efficiency curve with different loads.

output voltage gain of the converter is 20 times which is 7 times of the traditional boost converter, which is consistent with the analysis results. The capacitor voltage is related to the number of VMC. The first level is about $57 \mathrm{~V}$, the second level is about $114 \mathrm{~V}$, and the third level is about 171 $\mathrm{V}$, which is consistent with (7). The currents flowing through the switch $\mathrm{S}_{1}, \mathrm{~S}_{2}$ and the diodes are shown in Fig. 9(d)-(f). It can be seen that the currents flowing in the diodes are equal, that is, the currents flowing through each VMC are equal, and the voltage ripple is effectively suppressed.
Efficiency curve is shown in Fig. 10. The efficiency evaluation of the proposed novel converter is in the range of 80 $200 \mathrm{~W}$ output power, and the peak efficiency is about $97 \%$ when the output power $P_{0}$ is $160 \mathrm{~W}$.

\section{Conclusion}

A novel interleaved parallel high-gain DC/DC converter is studies in this paper based on voltage multiplication cell. The working principle of the converter topology, steady state analysis and experimental verification of the feasibility of the topology are completed. The conclusions are as follows:

(1) The voltage stress of the switch device and the diode is greatly reduced, so it is beneficial to reduce the circuit cost, reduce losses, and improve the efficiency of the converter by choosing a switching device with a lower withstand voltage.

(2) It can work in a small duty cycle state to achieve high gain of the circuit while reducing the current stress of the switching device.

(3) According to the different voltage level requirements of the application, the appropriate number of VMC units can be introduced to flexibly adjust the voltage level.

\section{REFERENCES}

[1] A. A. Fardoum and E. H. Ismail, "Ultra step-up DC-DC converter with 
reduced switch stress," in IEEE Transactions on Industry Applications, vol. 46, no. 5, pp. 2025-2034, Sept. 2010.

[2] G. Wu, X. Ruan, and Z. Ye, "Nonisolated high step-up DC-DC converters adopting switched-capacitor cell," in IEEE Transactions on Industrial Electronics, vol. 62, no. 1, pp. 383-393, Jan. 2015.

[3] Y. Ye and K. W. E. Cheng, "Quadratic Boost converter with low buffer capacitor stress," in IET Power Electronics, vol. 7, no. 5, pp. 1162-1170, May 2014.

[4] A. A. A. Freitas, F. L. Tofoli, E. M. Sá Júnior, S. Daher, and F. L. M. Antunes, "High-voltage gain DC-DC Boost converter with coupled inductors for photovoltaic systems," in IET Power Electronics, vol. 8, no. 10, pp. 1885-1892, Oct. 2015.

[5] M. Forouzesh, Y. P. Siwakoti, S. A. Gorji, F. Blaabjerg, and B. Lehman, "Step-up DC-DC converters: A comprehensive review of voltageboosting techniques, topologies, and applications," in IEEE Transactions on Power Electronics, vol. 32, no. 12, pp. 9143-9178, Dec. 2017.

[6] B. P. R. Baddipadiga, V. A. Prabhala, and M. Ferdowsi, "A family of high-voltage gain DC-DC converters based on a generalized structure," in IEEE Transactions on Power Electronics, vol. 33, no. 10, pp. 8399-8411, Oct. 2018.

[7] M. Shaneh, M. Niroomand, and E. Adib, "Non-isolated interleaved bidirectional DC-DC converter with high step voltage ratio and minimum number of switches," in IET Power Electronics, vol. 12, no. 6, pp. 15101520, May 2019.

[8] F. L. Luo and H. Ye, "Positive output cascade boost converters," in IEE Proceedings-Electric Power Applications, vol. 151, no. 5, pp. 590-606, Sept. 2004

[9] N. Zhang, G. Zhang, K. W. See, and B. Zhang, "A single-switch quadratic Buck-Boost converter with continuous input port current and continuous output port current," in IEEE Transactions on Power Electronics, vol. 33, no. 5, pp. 4157-4166, May 2018.

[10] D. Cao, S. Jiang, and F. Z. Peng, "Optimal design of a multilevel modular capacitor-clamped DC-DC converter," in IEEE Transactions on Power Electronics, vol. 28, no. 8, pp. 3816-3826, Aug. 2013.

[11] W. Li, Y. Zhao, Y. Deng, and X. He, "Interleaved converter with voltage multiplier cell for high step-up and high-efficiency conversion," in IEEE Transactions on Power Electronics, vol. 25, no. 9, pp. 2397-2408, Sept. 2010.

[12] K. Varesi, S. H. Hosseini, M. Sabahi, and E. Babaei, "Modular nonisolated multi-input high step-up DC-DC converter with reduced normalised voltage stress and component count," in IET Power Electronics, vol. 11, no. 6, pp. 1092-1100, May 2018.

[13] B. Wu, S. X. Li, K. M. Smedley, and S. Singer, "A family of two switch boosting switched capacitor converters," in IEEE Transactions on Power Electronics, vol. 30, no. 10, pp. 5413-5424, Oct. 2015.

[14] L. W. Zhou, B. X. Zhu, Q. M. Luo, and S. Chen, "Interleaved nonisolated high step-up DC/DC converter based on the diode-capacitor multiplier," in IET Power Electronics, vol. 7, no. 2, pp. 390-397, Feb. 2014.

[15] A. Rajaei, R. Khazan, M. Mahmoudian, M. Mardaneh, and M. Gitizadeh, "A dual inductor high step-up DC/DC converter based on the cockcroftwalton multiplier," in IEEE Transactions on Power Electronics, vol. 33, no. 11, pp. 9699-9709, Nov. 2018.

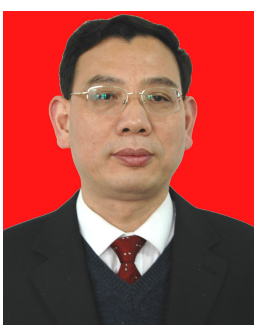

Yongle Ai was born in China. He received the B.S. degree in Power Electronics from Xi'an University of Technology, Xi'an, China, in 1987, received the M.S. degree in Electrical Engineering from Southwest Jiaotong University, Chengdu, China, in 1995, and the Ph.D. degree from the University of Stellenbosch, Stellenbosch, South Africa, in 2006.

He joined the Henan Polytechnic University from 1987 to now. He is currently a Professor at School of Electrical Engineering and Automation, Henan Polytechnic University, China. His research interests include multiphase AC machine control and power system filter. Prof. Ai is a member of Chinese Society for Electrical Engineering.

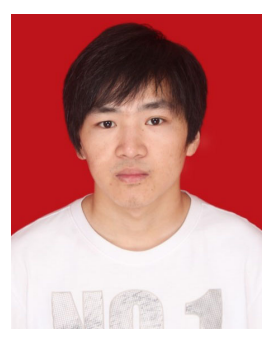

Xing Li was born in China. He received the B.S. degree in Electrical Engineering and Automation from Henan Normal University, Xinxiang, China, in 2016. He is currently pursuing M.S. degree in electrical engineering and automation at Henan Polytechnic University. His research direction is high gain DC / DC converter topology and control.

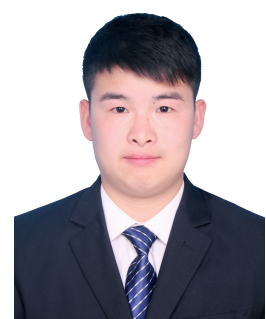

Qunfeng Liu was born in China. In 2017 and 2020, he obtained a bachelor's degree and a master's degree in electrical engineering and automation from Henan University of Technology, Jiaozuo, China. His current research interests include power system analysis and micro-grid control. Now, he works in Hebi Electric Power Company, State Grid Henan Electric Power Corporation. M.S. Liu is a member of Chinese Association for Artificial Intelligence.

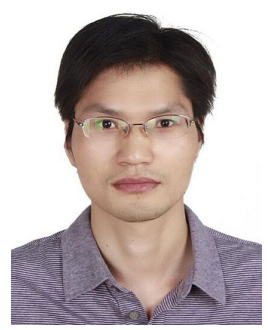

Haijun Tao was born in Henan, China, in 1980. He received the B.E. and M.S. degree from Henan Polytechnic University, Jiaozuo, China, in 2003 and 2006, respectively, and the Ph.D. degrees from Beijing University of Technology, Beijing, China, in 2016. He is currently a Associate Professor with the School of Electrical Engineering and Automation, Henan Polytechnic University. His research interests include electric drive, hybrid microgrid, switching power supply. 